\title{
Immortalizing the Mayfly: Permanent Ephemera: An Illusion or a (Virtual) Reality?
}

EPHEMERA (AN UNDERREPRESENTED and underresourced area of librarianship for many years) are finally coming of age — changing from nymph to adult mayfly, one might say. To be taken seriously by such an august body as the American Library Association's Rare Books and Manuscripts Section is something that ephemerists only dreamed of a decade ago. In preparing this article, it has been beneficial for me to address some of the issues surrounding ephemera: to think more generally (even philosophically) about what ephemera are, what we are trying to do with them, and for whom.

I am privileged to be Librarian of the John Johnson Collection of Printed Ephemera (named after John de Monins Johnson, 1882-1956), which is now in the Bodleian Library, University of Oxford. During the period between the two world wars, Johnson was inspired by his earlier work as a papyrologist in Egypt to begin his hobby of collecting, retrospectively, across the whole spectrum of printing and social history. Professionally, Johnson was Printer to the University of Oxford, and it was his work at the Press that enabled him to develop the Collection, providing him with a place to house it, and occasionally also making funds available for him to buy ephemera.

During his lifetime, Johnson collected ca. 1.5 million items, dating from 1508 to 1939 (his cutoff date), although he did add some later material, notably in the areas of Private Presses and developing technologies. He often used the phrase "printed ephemera," alternately with "the ephemera of printing," although neither was an "established" term during his lifetime. But a seminal work by that name was written by John Lewis in 1962, ${ }^{1}$ which drew heavily on the John Johnson Collection, then located at the Oxford University Press and called the "Constance Meade Memorial Collection of Ephemeral Printing.” In 1968, 12 years after Johnson’s death,

1. John Lewis, Printed Ephemera (Ipswich: W.S. Cowell, 1962). 
the Collection moved to the Bodleian Library. I began working with the Collection in 1985 and became its Librarian in 1988. Initially I continued sorting the material and creating indexes based on Johnson's original style. After a few years' dabbling in databases such as dBase IV and FoxPro, in 1995 we started to catalogue ephemera at an item-level, using an in-house tagged bibliographic format in allegro-C. ${ }^{2} \mathrm{We}$ currently have ca. 45,000 records, which will be augmented by an additional 65,000, courtesy of a Joint Information Systems Committee (JISC) funded project: Electronic Ephemera: Digitised Selections from the John Johnson Collection of Printed Ephemera. ${ }^{3}$

\section{The Importance and Value of Ephemera}

Ephemera collections are growing in importance. As Michael Twyman notes in his article in this issue of $R B M$, "Today, collections of ephemera that were acquired or built up decades or even centuries ago are being taken seriously by libraries, museums, and archives throughout the world" and "historians of many kinds-social, cultural, and business - now recognize their value as source material." Twyman summarizes the contribution made by ephemera to social history in these terms: "Every item of ephemera tells a story, or at the very least reveals specific information about something." Highlighting the example of trade catalogues and trade cards, he has expressed his belief that "without such items we would know very little in particular about the range of products and services available at a given time and place. Even when the actual products still exist somewhere, trade ephemera, especially catalogues and price lists, help to put them into a more general context."

I, too, find that the trade material in the John Johnson Collection is among the most fascinating in the Collection. Items such as the tradesman's list for John Watkinson of Scarborough (ca.1750) show us what was available at that time in towns remote from London, which can then provide a starting point for scholars to trace where the goods came from and how they got to their destination - thus adding to our understanding of the supply and distribution of produce, especially of luxury or exotic goods. In fact, trade cards and bill headings reveal information about all sorts of things: the cost of printing the cards themselves (Jessington Rozea, 1790), the types of ephemera printed ( $\mathrm{R}$. Wilson, a Devonshire printer, 1825), the activities of chapmen (Thomas Rimer, salesman, 1742), and the gauges of steel and iron wire (Millis \& Fossick, 1769). Trade cards contain evidence too of tradeswomen, of obsolete trades, of premises long since destroyed, of the display of merchandise in shop windows, and of the interiors of shops in the 18th and early 19th centuries. Illustrations of products are invaluable for research, as are those of manufacturing processes. The delight of ephemera is that they add pieces to the jigsaw puzzle

2. www.bodley.ox.ac.uk/johnson (Catalogue).

3. johnjohnson.chadwyck.com. 
that is social history_-pieces that cannot be found elsewhere, otherwise "missing links." My experience of over 20 years working with the John Johnson Collection has shown me the myriad ways in which ephemera can enhance and augment both academic and private research. I have often joked that I rarely have the same enquiry twice, and that is (almost!) a true statement!

Increasingly, academic books draw on ephemera to complement other sources. Several examples have been noted recently, including references to Beverly Lemire's The Business of Everyday Life, ${ }^{4}$ Consuming Angels: Advertising and Victorian Women by Lori Loeb, ${ }^{5}$ and Maxine Berg's Luxury and Pleasure in Eighteenth-Century Britain. ${ }^{6}$ Such books are putting ephemera firmly into the mainstream of academic publishing, and the teaching practices of their authors are creating generations of students who will habitually and naturally turn to ephemera to inform their own research. There are also many possibilities for creating ephemera-based publications that are more than just coffee-table books, such as Pets in America: A History by Katherine C. Grier, ${ }^{7}$ which can provide evidence in their respective fields that is not readily available elsewhere.

The Centre for Ephemera Studies at the University of Reading has compiled a register of ephemera collections in the United Kingdom, available both in hard copy and on $\mathrm{CD}^{8}{ }^{8}$ The Ephemera Society also includes links on its Web site to individual collections and special events in the United Kingdom, ${ }^{9}$ such as exhibitions, which is also done by the Ephemera Society of America for events in the United States. ${ }^{10}$ There are currently many initiatives to map collections of germane ephemeral material located in different institutions, including the Research Support Library Programme (RSLP) funded Backstage $e^{11}$ project for playbills and theater programs; Cecilia for music collections; ${ }^{12}$ and now the Arts and Humanities Research Council (AHRC) Concert Programmes project. ${ }^{13}$ Ephemera are also included in STC, Wing, and ESTC, all now under the umbrella of the English Short Title Catalogue, hosted (with free access) by the British Library. ${ }^{14}$

4. Beverly Lemire, The Business of Everyday Life: Gender, Practice and Social Politics in England c. 1600-1900 (Manchester: Manchester University Press, 2005).

5. Lori Anne Loeb, Consuming Angels: Advertising and Victorian Women (New York: Oxford University Press, 1994).

6. Maxine Berg, Luxury and Pleasure in Eighteenth-Century Britain (Oxford: Oxford University Press, 2005).

7. Katherine C. Grier, Pets in America: A History (Chapel Hill, N.C.: University of North Carolina Press, 2006).

8. Centre for Ephemera Studies, Dept of Typography \& Graphic Communication, University of Reading, Register of Ephemera Collections in the United Kingdom: Excluding Those in the Major Institutions and Others not Normally Available to the Public (Reading: University of Reading, 2003).

9. www.ephemera-society.org.uk.

10. www.ephemerasociety.org.

11. www.backstage.ac.uk.

12. www.cecilia-uk.org. 


\section{Print Culture vs. Book Culture}

Michael Twyman has also raised many interesting issues relative to the differences between print culture and book culture, showing us that the traditional focus on the book by printing historians is very narrow. He said that "To neglect ephemera ... is both to distort the history of the printing trade and to underestimate significantly its impact on society." Since ephemera have their own textual, graphic, and artefactual characteristics, Twyman argues that a new discipline of ephemerology is needed, to parallel bibliography, cartography, and philately. The various methods of printing that were specific to ephemera were rarely, if at all, used in book printing. Examples of printing processes unique to ephemera include security printing; packaging; fancy printing; tin-plate printing; printing of playing cards, paper bags, labels, and railway tickets; black borders on mourning stationery; cricket scorecards (which were printed on the spot); compound plate printing; die-stamping; embossing; lithography; folding and perforating paper and card; and die-cutting. Also, unlike books, ephemera were often printed on different substrates (colored paper, coated card, silk, cellophane, celluloid, wood, tin, and the like). And a major distinction is that in ephemera, image and text were integrated from the beginning.

\section{Teaching with Ephemera}

The John Johnson Collection was initially housed in shoe boxes kept under the beds in Johnson's home and contained potential illustrations for history books. The idea of illustrating children's reference works with primary source material was new at the time, and a children's encyclopedia was duly published by Oxford University Press. ${ }^{15}$ We are now revisiting this issue of teaching, by making primary source material available electronically. Julia Gardner and David Pavelich in their article in this issue of RBM argue that ephemera has become elitist, the preserve of graduate researchers and academics only. Others have pointed out that because ephemera relate to no specific academic field, funding to acquire and catalogue such resources is often lacking.

During my time working with the John Johnson Collection, I have seen three major shifts in ephemera "user-types." Early users included picture researchers who produced (mainly) coffee-table books of (mainly) Victoriana. This type of researcher has virtually disappeared from the John Johnson Collection, since the preference is to use resources that provide speedier image delivery, such as the Mary Evans Collection in London. ${ }^{16}$ The second group of users was made up of "serious"

13. www.cph.rcm.ac.uk.

14. http://estc.bl.uk.

15. Oxford Junior Encyclopaedia (12 vols.). Eds. Laura E. Saltet et al. (Oxford: Oxford University Press, 1948). 
researchers, often North American, who were writing "serious" academic books, which in many cases have become classics in their field and are informing current research. Today, I see much more use of the John Johnson Collection by students, including both graduates and undergraduates. It is particularly enlightening and encouraging to discover how much online resources are being used in undergraduate teaching. In support of a recent funding bid, Jim Secord, a professor in the Department of History and Philosophy of Science at Cambridge University and Director of the Darwin Correspondence Project, wrote: "The John Johnson Collection has not only provided the fundamental basis for much of my own research, I have used its unique resources extensively in teaching in the Department of History and Philosophy of Science at Cambridge. Most of my undergraduate students come from the sciences, and the lively images of everyday life from the collection play a major role in introducing them to history ... Having all this material well catalogued and available online will make a huge difference to my students. It will obviously be of use to postgraduates, but the greatest benefit will be to undergraduates, who will now be able easily to access these materials for their own essays and dissertations."

At Oxford University, the departments of History of Art, History, English, and Geography are all now making use of the John Johnson Collection, with some undergraduate theses being based on or informed by the Collection. For example, an Oxford University multimedia resource that focuses on the poems of Wilfred Owen, born in 1893 and died in action in 1918, incorporates virtual seminars and an online exhibition, drawing extensively on the John Johnson Collection for background material related to the First World War. ${ }^{17}$ As Gardner and Pavelich so rightly have said: ephemera allows undergraduates to connect with everyday life and thus evaluate evidence and refine critical thinking.

Furthermore, a developing trend in teaching is using ephemera in schools. There is enormous potential here, but we are constantly coming up against the underfunding of ephemera collections and the relative novelty of Web-based teaching resources. Schools in the United Kingdom expect resources to be tailored to the core curriculum - which requires a special kind of expertise. The CILIP, or Chartered Institute of Library and Information Professionals (formerly The Library Association), addressed this issue in its report, The Stuff of History: ${ }^{18}$ "The significance of ephemera for the teaching of history in schools has already been demonstrated. In particular, Longman's 'Jackdaw' series from the 1960s, and more recently the ephemera collections in facsimile sold by the Public Record Office (now the National Archives), have shown how effective reproductions of ephemeral documents of the past can be as part of a

16. www.maryevans.com/.

17. www.hcu.ox.ac.uk/jtap.

18. Chartered Institute of Library and Information Professionals (Great Britain), The Stuff of History: Report of the Working Party on Ephemera Set Up by CILIP ([London]: CILIP, 2003). 
teaching pack. The educational potential of ephemera at all stages of education has increased beyond measure in recent years with the widespread availability of electronic methods of delivering images." Our new JISC Electronic Ephemera will be freely available to schools in the UK. I believe firmly that the audience is "out there" and that making ephemera digitally available on the Web (supported, of course, by detailed metadata) can only be immensely beneficial to all user groups, including "Joe Public" whose interests are as varied and as specific as those of many researchers. Surely, the excellent Library of Congress American Memory project exemplifies this. ${ }^{19}$ It has benefited American citizens enormously, and Britons deserve a similar resource.

\section{Literary Ephemera}

In the eliminations of the 1930s, the Bodleian claimed that ephemera were of "no literary or artistic value" (quoted by Twyman). However, there are several articles in this issue of RBM devoted to literary ephemera, including: ephemera that have been generated by Ben-Hur and Jane Eyre; the extra-illustration of books by John M. Wing of the Newberry Library; and Apazines. In the first two cases, the authors present different arguments about the importance of the memorabilia surrounding the novels. Jon Solomon identifies hundreds of artifacts and items of ephemera produced in the wake of the novel Ben-Hur-Ben-Hur flour, perfume, steamer, coffee, fly wheel ... the list is endless, and fascinating — that created a marketing phenomenon before "popular culture" was appreciated or studied. Barbara Heritage describes ephemera relating to Jane Eyre - a gauge of reader response to the novel-which was mostly produced during the 20th century in the United States.

The use of ephemera in the study of literature is a growing field. Detailed cataloguing of the items now allows researchers, at the click of a button, to discover the existence of what would previously have taken many years of ploughing through reference sources. An example in Britain is the Backstage project, for which several institutions (including the John Johnson Collection) have automated the cataloguing of their playbills and programs. This is quite a change from the way in which, just fifteen years ago, an American volunteer compiled a manual cross-index of nontheatrical performances in theaters (clowns, magicians, acrobats, dance, circuses, and so on). If only one had a crystal ball!

\section{Medical Ephemera}

Historic medical ephemera are important not only for the study of medicine-including medical practice, diseases, and their social context - but also for study of the book trade. Our recent cataloguing and digitization of book trade material 
in the John Johnson Collection reveals how wide was the range of products sold by booksellers - not only patent medicines, but also scientific, mathematical, and musical instruments, as well as fancy goods such as Tunbridge Ware. Significant collections exist in the Wellcome Library in London, which holds ca. 30,000 items of medical ephemera from the 17 th to 21 st centuries, with its strengths in the 19th and 20th centuries. Important medical ephemera are also to be found in the Sir Hans Sloane Collection in the British Library (two volumes, containing 400 items of mainly 17 th-century advertisements), and a volume of advertisements for quack medicines collected by John Bagford (1650-1716), which is part of the British Library's Harley Collection. Such early collections are invaluable, as this material has all but disappeared. As Twyman notes, we only have the tip of the iceberg now: we are too late for so much ephemera.

\section{Private Collectors}

It is fortunate that private collectors have donated specialized collections to fill the many gaps that exist in institutional holdings for subject areas in which librarians would not necessarily collect. Throughout history, libraries have collected books or ephemera in a general way, but a specialist collection compiled by an individual, be it of historic or modern material, has a unique value far beyond the sum of its parts and is indispensable. This "added value" is the subject of William Barlow's article in this issue of $R B M$, fascinating both for his many insights into the issues raised by collecting ephemera as well as the description of his own collections. He states that "developing a completely ephemeral collection from scratch is difficult for a librarian to justify doing, and even more difficult to accomplish." Libraries such as the Bodleian with collections like the John Johnson Collection are so all-embracing that it would not be feasible to collect in depth across all possible subject areas. Even specialized libraries—such as the Wellcome Institute, the lamented Theatre Museum (no longer a separate museum but a branch of the Victoria \& Albert Museum), or the Women's Library in the London Metropolitan University-while they have a more restricted remit, still face the challenge of insufficient resources-financial as well as staffing-to maintain their collections.

\section{Modern Ephemera}

This brings us neatly to the question of modern ephemera. Do we need to be collecting them and how? John Johnson believed that ephemera should survive by chance-that history should make an unconscious selection of the past. Consequently, with only a few exceptions, he collected retrospectively: he explained that he did not collect the ephemera of the Second World War because he could have filled rooms with them. However, since Johnson's time (but as he accurately 
anticipated), the market has caught up with ephemera, and we can no longer afford to buy tomorrow what we can collect free of charge today. Additionally, there is a danger that records might be lost. A real urgency for the necessity of collecting evidence of ethnic minorities is raised in Georgia B. Barnhill's article in this issue of $R B M$, in relation to the work on African Americans that has been done by Randall K. Burkett, Curator of the African-American Collection at Emory University. There is a duty to preserve the ephemera that shed light on these communities, especially as there may be no other records of them.

We live in a throwaway society - which is increasingly becoming a recycling society-in terms of the loss of ephemera, echoing the salvage efforts of the world wars. Most people do not keep their junk mail or the tourist leaflets from their holidays. Many have limited space and cannot afford to hoard ephemera, although fortunately not all. However, we have to recognize that, by collecting contemporaneously, we do change the nature of ephemera: for the material then survives by design rather than by chance.

When the John Johnson Collection came to the Bodleian, a decision was made to collect contemporaneously. We accept ca. 11,000-15,000 items a year, which are sorted and stored for the future. We make special collections of election ephemera and of national events: the death of Diana, Princess of Wales; the Queen's jubilee; the Millennium celebrations (including the Millennium Dome), and the like. Our perception of the ephemera around us, of course, differs from our perception of historic material and is also different from the perspective of future users of the material we are currently collecting. While we might decry the "nuisance" aspect of junk mail, it will shed its familiarity in 70-100 years. It will have lost its context but will have retained its value as a purveyor of information. Students will study the way in which messages were designed and imparted, noting new features such as holograms, Web and e-mail addresses, and changes in postcodes, just as we are helped in dating material by noting the presence or absence of a street number around 1762, or use changes in telephone numbering systems to date 20th-century material. In most institutions (although not all), modern ephemera are collected for the future but are not catalogued. Because they are in copyright, they cannot be digitized at this time. Perhaps the 70 years' copyright restriction (for anonymous works) represents an ideal time frame to assess what we have collected.

The question of degrees of ephemerality is considered by Gregory J. Prickman's article in this issue of $R B M$, in which he points out some of the difficulties collecting Apazines since they are only available to a restricted mailing list. But though few of them have survived, they hold enormous potential for literary and cultural research. 
Even more difficult to collect are items such as Chinese ritual paper offerings, which were not meant to survive at all, even by chance, but rather were intended to be destroyed by ritual. Finally, there is the issue of extending the concept of ephemera to include "born digital" materials, much of which has already disappeared.

I personally take refuge in the fact that I look after the John Johnson Collection of Printed Ephemera (although I do extend that concept to include photocopied documents and, occasionally, printouts). Yet I also think that with much of today's ephemera, print is already being replaced by electronic formats. Just as contemporary literary manuscripts are for the most part now being edited on hard drives and memory sticks that fail to document the creative process, so, too, will advertising, holiday brochures, timetables, and publishers' and CD catalogues pass onto the Web (where many already exist) and be lost to future generations, unless the professional communities currently considering such matters act quickly.

\section{Dealers}

On the topic of the contribution made by dealers to ephemera, four representative dealers from two establishments (aGatherin' and Margolis \& Moss) provide their different perspectives on dealing with ephemera in a collective article in this issue of RBM. They characterize themselves as: Garbage Hound (Robert Dalton Harris) and Teacher of the Narrative (Diane DeBlois); Artist and Photographer (David Margolis) and Follower of the Esthetics (Jean Moss). All provide insight into the work they undertake in finding, acquiring, sorting, and describing ephemera, and the affiliations they maintain with special collections librarians. The relationship that dealers have with ephemera is a particularly privileged one: they might "curate" ephemeral collections of ephemera or, in other cases, actually rescue material. They tend to see more ephemera than most of us ever will, and, since they have to describe and evaluate them, they really have to register what they are seeing. Thus they are able to put the material into context and assess its rarity. They add value to the collections they sell, whether in the description and evaluation of a pre-existing collection or in the compilation of specialist collections destined for public collections (such as the history of the atomic bomb compiled by aGatherin'). Good dealers are experts in their field and are, speaking from my own experience, generous in sharing their knowledge. In assigning a commercial value to it, they produce a scale of values that impacts on our judgment of ephemera.

The Internet has changed the way in which ephemera are sold today. Many dealers produce online catalogues, with descriptions that are often accompanied by digital representations. Such catalogues should be archived. And then there is eBay, which, whether you love or hate it, has undoubtedly made an impact on the way in which ephemera is bought and sold. I very much like the idea of eBay as an additional 
research tool, as described by Solomon, who used it to find additional evidence for the popularity of Ben-Hur and the commercial products it inspired. But is anyone archiving the content of eBay, where so many items are in private hands, surfacing for a few days only to disappear again? Such a thought is tantalizing and is the reason the Ephemera Society in the United Kingdom is encouraging private collectors to catalogue and digitize, even if they subsequently sell an item-because it is all part of "the record."

\section{Storage and Preservation}

Most of us deal with old and overcrowded storage: there is most definitely no spare space in the John Johnson Collection at the current time, although I hope this might change for the better in the future. Actually, in terms of the material itself, the John Johnson Collection is relatively fortunate. We are improving the housing of our material by using acid-free folders to divide material into smaller groups within boxes. We are increasing our use of melinex (or mylar) because reguarding the material with flexible Japanese tissue means that it will be more vulnerable (with Johnson's brittle hinging, we would not have been able to digitize the verso or last page).

\section{Exhibitions}

Since the seminal exhibitions of the 1970s-John Johnson Collection (Bodleian Library) and This is Ephemera (Ephemera Society) - there have been several other exhibitions that have presented ephemera to the public. Twyman mentioned Ephemera, les Imprimés de nos Jours at the Musée de l'Imprimerie in Lyon (2001) and was too modest to refer to his major exhibition on chromolithography, Couleurs: Les Prouesses de la Chromolithographie, held at the same venue (16 November 2007-17 February 2008). He also referred to Questions d'Étiquettes at the Bibliothèque Forney in Paris in 2002. I have recently curated one exhibition: A Nation of Shopkeepers (2001) and co-curated another: Children's Games and Pastimes (2005-2006). In the United States, there have been recent exhibitions at the Grolier Club, including Quack, Quack, Quack: Sellers of Nostrums in Prints, Posters, Ephemera and Books and a display of material from the Winterthur Library. There are many other examples of how ephemera are increasingly being used in exhibitions on a wide range of subjects. Ultimately, by their very nature, ephemera are eminently exhibitable.

\section{Cataloguing}

The title of my paper, Immortalizing the Mayfly: Permanent Ephemera: An Illusion or a (Virtual) Reality? reflects current concerns that I have, especially those relating to our JISC-funded Electronic Ephemera project. With the identification of ephemera collections comes the problem of describing them and making 
them available. Ephemera are difficult (or "vexing" in the words of Gardner and Pavelich): difficult to catalogue, arrange, or even define (not to mention how to pronounce the very word, itself, and whether it is to be used in the singular or plural!). Ephemeral materials are not books, which benefit from a long history of collecting, cataloguing, and bibliographic description that is now increasingly automated and enhanced. They are not archives, which are being made available in the 21st century through general descriptive frameworks such as EAD and ISAD $(G)$. Ephemera have mostly survived by chance, not just in libraries, but also in museums, archives, local studies collections, and other institutions, each of which has its own ways of describing the objects in its care. Furthermore, few ephemera collections have a team of staff: often they have no dedicated staff at all and are regarded (in Twyman's words) as of "marginal concern."

However, we have moved beyond such attitudes as the Bodleian's call for the elimination of ephemera, and Rutgers University Library's: “they are ephemeral in nature and do not warrant cataloguing" (cited by Barnhill). Yet the underresourcing of ephemera is very common indeed. It is crucial that this be rectified if we are to do justice to our collections - to "surface" them. The Bodleian is fortunate to have a full-time post for "Librarian of the John Johnson Collection," but my time is divided between inquiries, acquisitions, supervision of volunteers and trainees, and cataloguing. Only by applying for funding have we managed to make a relatively significant dent in the John Johnson Collection cataloguing backlog: otherwise we would be reliant on volunteers who come in for a day a week and part-time trainees (who stay for two to three months and then move on to the next department). The cataloguing backlog in the John Johnson Collection of at least a million items is not a serious issue in the context of the Bodleian Library for which, as is the case everywhere, funding is a huge problem. One day, perhaps this will change and we will see more online catalogues of ephemera. Meanwhile, I continue to wear my very good pair of blinkers when I go into the Collection, in order to ignore the claims of the material I am not currently working on.

The question of whether to catalogue ephemera at an item or collection level has been raised repeatedly, especially in the context of archives or discrete collections. In my view it is essential to have collection-level descriptions-guides to the contents of the boxes - so that readers can see at a glance what sort of material there is and how it is arranged. However, with collection-level indexes in place for the majority of the John Johnson Collection (which include more than have been posted on our Web site), what ephemera cry out for, in my opinion, is to be catalogued at an item level. The digital era has also impacted upon the type of cataloguing: it is not unlikely that descriptive cataloguing for ephemera will be accompanied by an image, and possibly an OCR file. 
Cynics and perfectionists would argue that ephemera cataloguing is a mess, and it is! We have effectively "missed the boat"- though not in terms of creating specific rules for cataloguing ephemera, which might still be done. DCRM(B) has made it easier to catalogue ephemera than it was using AACR2. However, it is too late to create rules everyone would follow: too many different catalogues exist in too many unique institutional formats. We should not forget that many catalogues of ephemera exist in museums and archives, each following its own cataloguing conventions. We could—and should—make cross-searching easier by establishing some common minimum fields: first line or title, names, date, subjects, etc. We should all use thesauri, preferably the same ones, such as the Library of Congress Name authorities (supplemented by other name authorities where necessary), $\mathrm{LCSH}$, and one of the standard iconographic thesauri. I believe that a union catalogue of ephemera is impossible because it is so difficult to ascertain that an item of ephemera is duplicated elsewhere. In addition, many ephemeral materials are not in institutions, yet are still being catalogued and digitized, and this all adds to the corpus of knowledge.

I have in all conscience to say, however, that I remain totally unconvinced that MARC is the best format to use for cataloguing ephemera. The problem is that MARC was developed for books. If the creators of MARC had started with ephemera, they would surely have devised a very different structure. Ephemera do not systematically have any of the components of title pages, which form the basis of book cataloguing. While there may be a title (or at least a first line), it is unusual for users of ephemera to search by it unless they are looking for a specific item. They might perhaps search by keyword. Ephemeral materials sometimes include an author, a date, or an imprint — but many have none of these. There could be (as Twyman discusses in his article) several variants or "editions" of a particular item, but it is very rare to have an edition statement. Furthermore, most ephemera do not typically share the physical characteristics of books: gatherings, pagination, binding, and so on. To refer back to Twyman's article, ephemera are printed in many, varied ways. Often, items of ephemera are a combination of print and image - an inextricable link, which has little to do with, for example, an illustrated book, where the same text might be illustrated by different artists. As Twyman points out in his article, ephemera lie somewhere between book and print culture.

Before trying to squeeze them into a format devised for something else, it is fundamental that we look at what ephemeral materials are, and what aspects of them can and should be catalogued. Ephemera can provide so much information, and that information should be catalogued: in fact, the provision of as many access points as possible is one of the satisfactions of cataloguing ephemera. It is for this reason that I developed, together with the Bodleian's allegro expert, David 
Helliwell, an in-house format for cataloguing ephemera - a tagged, bibliographic format, not dissimilar to MARC (and exportable in a variety of formats), but developed from working with ephemera, from understanding the needs of users of ephemera, and from grappling with the specific issues that relate to ephemera. For example, what interests us with trade cards surely are the tradesmen, their addresses, trade signs, trades and products, the iconography of the card, and so on. We should be cataloguing the content of the item, including, of course, the images. In book cataloguing, the subject is reflected only in Library of Congress Subject Headings. But because ephemera are used in so many different ways, they need to be catalogued in more detail.

I am not unaware that to advocate a departure from MARC and AACR2 or $\operatorname{DCRM}(\mathrm{B})$ lays me open to criticism. The problem that I see in so doing is that a stand-alone catalogue sacrifices the ability for cross-searchability with books in the Library's OPAC. However, "mainstream" book cataloguers often make value judgments about the validity of including certain information (such as names that are mentioned on posters or broadsides), on the grounds that to do so would clutter the book catalogue with trivial references. Much information is excluded in traditional cataloguing — and not just in the interest of time. Perhaps I am wrong, but I believe that any information contained in an item of ephemera has its own validity. But then again, since I have the privilege of cataloguing only ephemera, this could radically skew my perception from the perception of those who catalogue books as well as ephemera.

The John Johnson Collection online catalogue is far from perfect, and the Web version needs to be made significantly more user-friendly (although the ProQuest application achieves this). There is much retrospective name- and subject-authority work to be done. Some of the records are poor, having been transferred from finding aids in dBase IV on the grounds that "a poor record is better than no record." The catalogue could also be criticized for not going far enough in dealing with those issues with which many librarians (myself included) are less comfortable, such as identifying printing processes, typefaces, substrates, let alone the aesthetic considerations of design or typographic layout. Once you start to look at what ephemera are (rather than what they are not) through the eyes of different types of users (notably printing historians such as Twyman), you begin to realize how much more we should be providing to do justice to the material in our catalogue records. Even so, it is very exciting to see the various strands of the John Johnson Collection being drawn together through cross-references that are automatically established. This is, for me, the raison d'être of cataloguing. Ephemera could be arranged physically in many ways: by subject, by genre, by place, by date. The cataloguing enables the researcher to create virtual arrangements of the material according 
to his or her own interests, to find material by artist, printer, or tradesman, just to name a few. While we may argue about the form of cataloguing, we should all continue to expose our collections. And we should keep focused on creating a corpus of documented material for scholars and others, even if (as asserted by Barnhill) they have not yet caught up: they will. We can no longer allow ephemera to sit around in dusty boxes, actually or virtually labeled "difficult material."

\section{Digitization}

The dissemination of ephemera, as Twyman acknowledges, is being greatly assisted by digitization. Digitization is ephemera’s "best friend," making them readily available to a much wider community. Catalogue records on their own are arid means of finding a particular item or information about an item. But coupled with a digital image, they come alive. Many users' inquiries can be answered adequately from the digital resource, or "surrogate." The cataloguing-only Backstage project (which has been crawled by Google's search engines) has generated many inquiries (usually from family historians), while projects that combine cataloguing and digitization have generated very few. In the end, it saves the time of both curators and users. Making the ephemera collected by John Johnson available throughout the world is one of my principal aims. Not only does digitization help to preserve the originals, but the detailed accompanying metadata enables viewing of the Collection in an infinite number of ways according to the researchers' interests. In a collection where the material is arranged mostly by subject, we can create virtual sequences. ${ }^{20}$ Another positive outcome of the Bodleian's digitization program will be the provision of a faster ordering service for predigitized images.

The path has not been entirely smooth: some of the first John Johnson Collection digitization projects have less than perfect images. However, I do not regret jumping on this particular bandwagon, as experience in the area has benefited the next project. Of course, digitization is not popular with everyone. There are those who have not entered the computer age. There are also those who see people like me as restricting access to the real thing, to removing that very great pleasure that comes with browsing, of the chance discovery, of serendipity. Are they right? In what ways are we changing the very nature of ephemera in this quest to make it available in every conceivable way except that of touching, of handling the artifact itself? Are we depriving users of the joy of discovery? But could our catalogues ever achieve that even if it were desirable? Some claim that we are indeed removing the "fugitive" nature of ephemera. 
There are also people, like Twyman, whose inquiries are not adequately served by digitization: they need to actually see the hollows in the paper from the letterpress printing, the lines, the dots. They want to use their physical magnifying glass, not the one on the computer screen, however good the image, whatever the resolution. There are also those who are skeptical of the longevity of the images and who still consider microfilm to be the ultimate preservation medium. However, we hope that we now know enough about refreshing and migrating data to maintain our digital surrogates. We also have to guard against indiscriminate digitization by consulting our users and stakeholders, by analyzing use of our physical collections to determine research trends, and by prioritizing material for digitization.

Even when preaching to the converted, there are dangers in mounting collections on the Web. Scholars tend to assume that the digital resource is complete. However many warnings you post on the Web, they will take the easy option of searching what is there and not asking questions beyond what is readily available. There is a growing and worrisome trend: now that so very much is available on the Web, will users assume that you have, in the space of a few years, catalogued and digitized one and a half million items?

So, to conclude: are we immortalizing the mayfly? On the whole, I think we are. We create multiples of her: she can be seen in as many locations as desired. She will never die. But perhaps we will never truly capture her essence. We can use as many terms as possible to describe her, we can digitize her, but we can never replace her.

\section{INDEX TO ADVERTISERS}

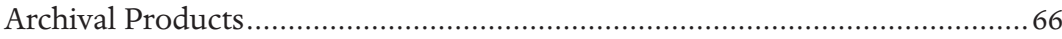

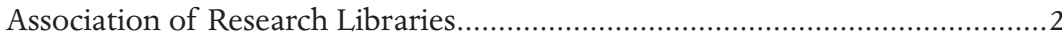

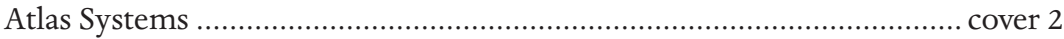

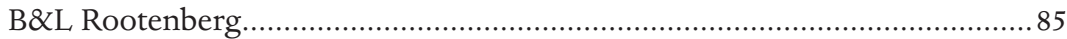

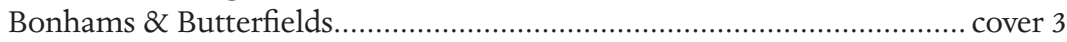

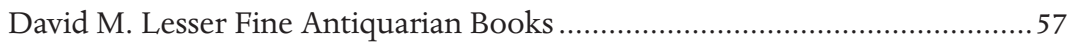

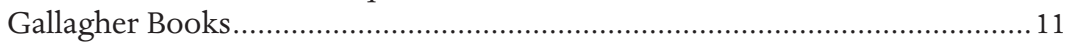

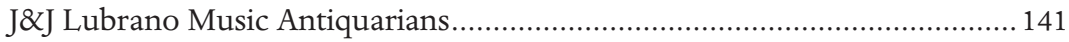

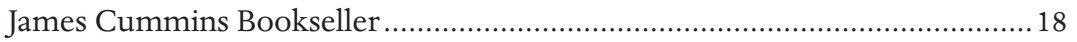

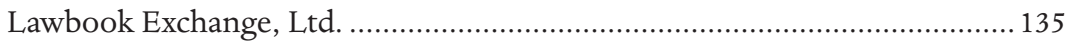

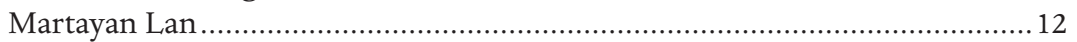

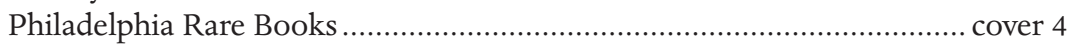

Priscilla Juvelis Rare Books ....................................................................... 1

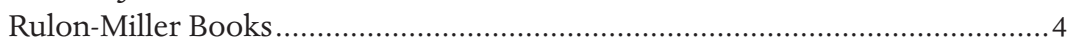

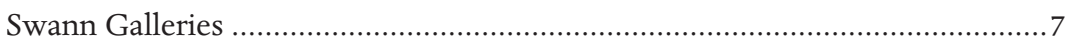

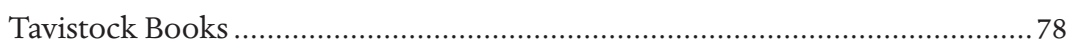

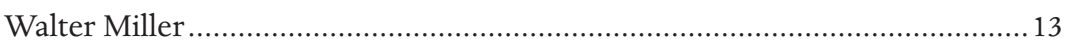

